\title{
Bone mineral content and body size 65 to 100 weeks' postconception in preterm and full term infants
}

\author{
A HORSMAN, S W RYAN, ${ }^{*}$ P J CONGDON, ${ }^{*} \mathrm{~J}$ G TRUSCOTT, AND M SIMPSON \\ MRC Bone Mineralisation Group, Department of Medical Physics and ${ }^{*}$ Regional Neonatal Surgical and \\ Intensive Care Unit, The General Infirmary, Leeds
}

SUMmARY A total of 36 preterm and 22 full term infants were weighed and measured at 65 to 100 weeks' postconception. It was found that the preterm infants were on average significantly lighter by $1008 \mathrm{~g}$ and shorter by $3.8 \mathrm{~cm}$ than those born at full term. Despite the smaller size of preterm infants, mean values of bone mineral content in the mid-forearm were not significantly different between the two groups. In contrast, near 40 weeks' postconception the mean bone mineral content observed in 35 of the preterm infants was significantly smaller than that observed in eight of the full term infants.

Our results suggest that there is a phase of rapid mineral accretion between 40 and 60 weeks' postconception. This 'catch up' in mineral accretion reduces the perinatal mineralisation deficit that might otherwise persist into childhood.

In most preterm infants, by 40 weeks' postconception there is a substantial deficit in bone mineral accretion relative to full term infants observed at birth. ${ }^{12}$ Application of single photon absorptiometry to the mid-forearm has shown that those most seriously affected are infants born with extremely low birth weight (that is, $<1000 \mathrm{~g})^{3}$; by 40 weeks their bone mineral content is lower by about $35 \%$ after accounting for reduced weight and crown-heel length. ${ }^{2}$ Preterm infants with higher birth weights are similarly undermineralised by about $20 \% .^{1}$

Attempts to accelerate postnatal mineral accretion in preterm infants have had variable success (unpublished observations). ${ }^{45}$ Radiographically detectable osteopenia has reportedly been ameliorated by vitamin D supplementation. ${ }^{6}$ Our own measurements, however, did not show more rapid mineral accretion in preterm infants when the daily vitamin $D_{2}$ intake was raised from the standard 400 IU to $1000 \mathrm{IU}$ (unpublished observations). There is stronger evidence that the rate can be increased by mineral supplementation, ${ }^{47}$ but the response is dependent on the way the supplement is administered, its amount, and whether or not vitamin D extra to the standard daily supplement is added. ${ }^{4}$ Our results using mineral supplemented formula feeds showed a significant improvement in accretion rate up to 40 weeks' postconception ${ }^{8}$; however, by
40 weeks the preterm infants were still undermineralised relative to full term peers.

The thrust of supplementation studies towards restoration of mineral accretion rate to its in utero values arises partly from the desire to minimise known complications of neonatal osteopenia. It is not known, however, whether this is simply a short term problem or whether it has a long term impact on skeletal development. The purpose of the present study was to compare weight, crown-heel length, and bone mineral content in preterm and full term infants 65 to 100 weeks' postconception in order to determine whether or not effects of prematurity were detectable beyond the neonatal period. Differences in weight gain and linear growth were anticipated and particular emphasis was therefore placed on the bone mineral measurements. ${ }^{910}$

\section{Patients and methods}

This study was authorised by the local ethics committee. In all, 58 infants born between May 1984 and February 1988 were examined. They were all white singletons whose parents gave informed consent for the investigations to be performed. Of the 58,36 infants (18 of each sex) had been born prematurely and comprised the 'preterm group', group $P$. The remaining 22 (15 boys), who were 
born after approximately 40 weeks' gestation, comprised the 'full term group', group F, and served as controls.

Infants in group $\mathrm{P}$ had been born in or referred to our neonatal intensive care unit during a 30 month period commencing July 1984 . While in the unit they had been included in studies of the efficacy of various feeding regimes in promoting bone mineral accretion during the neonatal period. ${ }^{8}$ After discharge from the unit they all received conventional formula feeds.

Of the 22 full term infants in group $F$, nine had previously served as controls in another study when much younger, and participated in the present investigation because their parents were prepared to bring them from home for remeasurement. The other 13 infants were recruited from the local general paediatric ward and were measured while inpatients. They were selected initially on the basis of age and race from all cases presenting with acute non-serious illness who had no history or signs of bone, liver, or renal disease. Patients who had received medication that in any way might have influenced mineral metabolism were rejected, as were those who had not been born at full term (assessed from birth case notes) and those who were below the 10th centile for weight on standard charts. ${ }^{11}$ With four exceptions, all the full term infants received formula feed from birth; the remainder were breast fed, with weaning commencing at about 3 months of age.

Gestational age (completed weeks), calculated from maternal menstrual history and confirmed by either external examination ${ }^{12}$ or ophthalmoscopic examination of the lens, ${ }^{13}$ had been documented in each case. For group $\mathrm{P}$, gestational age ranged from 26 to 31 weeks with mean (SD) $28.5(1 \cdot 8)$ weeks and for group $F$ ranged from 37 to 42 weeks with mean $39.3(1.5)$ weeks.

On up to three occasions but usually two, near to 40 weeks' postconception and in the period 65 to 100 weeks' postconception, the bone mineral content $(\mathrm{mg} / \mathrm{cm})$ was measured at the middle of the forearm of each infant by photon absorptiometry as described in previous publications. ${ }^{13}$ The radiation exposure involved in this procedure is very small, and only a narrow area of the forearm is irradiated during a scan; skin entrance dose is $0.03 \mathrm{mGy}$ per investigation. Weight $(\mathrm{g})$ and crown-heel length $(\mathrm{cm})$ were usually measured whenever a scan was performed.

In the postconceptional age range 37 to 45 weeks, complete data (that is weight (W), crown-heel length (CHL), and bone mineral content (BMC)) were obtained in 34 of the 36 preterm infants comprising group $\mathrm{P}$; one had no measurements taken in that period, and in one infant crown-heel length was not measured. Results obtained at that time ('term data') are denoted by W1, CHL1, and BMC1, with PA1 denoting postconceptional age. Eight randomly selected members of group $\mathbf{P}$ (five boys) were also scanned while attending outpatient clinics when aged between 46 and 53 weeks' postconception; the resulting 'intermediate data', denoted by W2, CHL2, BMC2, were complete except in one case in whom weight and crown-heel length were not measured on the day of that scan. All 36 infants in group P were later scanned in the period 68 to 101 weeks' postconception, again when they attended for outpatient review. In three infants, neither weight nor crown-heel length was measured on the day of the final scan. Results obtained at that later time ('endpoint data') are denoted by $\mathrm{W} 3, \mathrm{CHL} 3$, and BMC3.

Soon after birth, in the postconceptional age range 39 to 43 weeks, complete data (that is, W1, CHL1, and BMC1) were obtained in eight (four boys) of the 22 full term infants comprising group $F$. All 22 infants were later scanned in the period 65 to 102 weeks' postconception. The data obtained in that interval (W3, CHL3, and BMC3) were complete. None of the full term infants had measurements taken at intermediate times.

Descriptive statistics for the term, intermediate, and endpoint data are given in tables 1,2 , and 3 respectively.

\section{STATISTICAL ANALYSIS}

Calculations performed on the data included simple linear regression, $F$ tests of the significance of the difference in slopes of regression lines,${ }^{14}$ and analysis of variance and covariance using type of birth

Table 1 Descriptive statistics for observations of weight (W), crown-heel length (CHL), and bone mineral content (BMC) obtained around 40 weeks' postconception in both the preterm $(P)$ and full term groups $(F)$ (term data). $P A$ denotes postconceptional age

\begin{tabular}{|c|c|c|c|c|}
\hline & $\begin{array}{l}\text { PAl } \\
\text { (weeks) }\end{array}$ & $\begin{array}{l}W 1 \\
(g)\end{array}$ & $\begin{array}{l}C H L 1 \\
(\mathrm{~cm})\end{array}$ & $\begin{array}{l}B M C l \\
(\mathrm{mg} / \mathrm{cm})\end{array}$ \\
\hline \multicolumn{5}{|l|}{ Group P: } \\
\hline Mean & $40 \cdot 4$ & 2620 & $46 \cdot 15$ & $118 \cdot 8$ \\
\hline SD & 1.6 & 739 & $4 \cdot 14$ & $41 \cdot 3$ \\
\hline Maximum & $44 \cdot 6$ & 4005 & 52.90 & $224 \cdot 0$ \\
\hline Minimum & $37 \cdot 4$ & 1270 & $38 \cdot 70$ & $65 \cdot 0$ \\
\hline No of subjects & 35 & 35 & 34 & 35 \\
\hline \multicolumn{5}{|c|}{ Group F: } \\
\hline Mean & $41 \cdot 0$ & 3344 & $50 \cdot 38$ & $190 \cdot 9$ \\
\hline SD & $1 \cdot 2$ & 401 & 1.33 & $20 \cdot 4$ \\
\hline Maximum & $42 \cdot 7$ & 3885 & $52 \cdot 50$ & $216 \cdot 0$ \\
\hline Minimum & $39 \cdot 1$ & 2795 & $48 \cdot 60$ & $165 \cdot 3$ \\
\hline No of subjects & 8 & 8 & 8 & 8 \\
\hline
\end{tabular}


Table 2 Descriptive statistics for observations of weight (W), crown-heel length (CHL), and bone mineral content (BMC) obtained between 46 and 53 weeks' postconception in the preterm group $(P)$ (intermediate data). No intermediate data on group $F$ were available

\begin{tabular}{lllll}
\hline & $\begin{array}{l}\text { PA2 } \\
\text { (weeks) }\end{array}$ & $\begin{array}{l}\text { W2 } \\
(\mathrm{g})\end{array}$ & $\begin{array}{l}\text { CHL2 } \\
(\mathrm{cm})\end{array}$ & $\begin{array}{l}\text { BMC2 } \\
(\mathrm{mg} / \mathrm{cm})\end{array}$ \\
\hline Group P: & & & & \\
Mean & $49 \cdot 6$ & 4029 & $53 \cdot 71$ & $207 \cdot 9$ \\
SD & $2 \cdot 8$ & 701 & $3 \cdot 71$ & $44 \cdot 5$ \\
Maximum & $52 \cdot 7$ & 4850 & $59 \cdot 00$ & $286 \cdot 3$ \\
Minimum & $46 \cdot 1$ & 2950 & $48 \cdot 80$ & $155 \cdot 7$ \\
No of subjects & 8 & 7 & 7 & 8 \\
\hline
\end{tabular}

Table 3 Descriptive statistics for observations of weight $(W)$, crown-heel length $(\mathrm{CHL})$, and bone mineral content (BMC) obtained in the postconceptional age range 65-100 weeks approximately in both the preterm $(P)$ and full term groups $(F)$ (endpoint data)

\begin{tabular}{lcccc}
\hline & $\begin{array}{l}P A 3 \\
(\text { weeks })\end{array}$ & $\begin{array}{l}\text { W3 } \\
(\mathrm{g})\end{array}$ & $\begin{array}{l}\text { CHL3 } \\
(\mathrm{cm})\end{array}$ & $\begin{array}{l}\text { BMC3 } \\
(\mathrm{mg} / \mathrm{cm})\end{array}$ \\
\hline Group P: & & & & \\
$\quad$ Mean & $86 \cdot 2$ & 8148 & $71 \cdot 23$ & $301 \cdot 8$ \\
SD & $7 \cdot 9$ & 1229 & $4 \cdot 00$ & $80 \cdot 0$ \\
Maximum & $101 \cdot 0$ & 10750 & $78 \cdot 50$ & $490 \cdot 3$ \\
Minimum & $68 \cdot 4$ & 5150 & $60 \cdot 90$ & $184 \cdot 9$ \\
No of subjects & 36 & 33 & 33 & 36 \\
Group F: & $77 \cdot 2$ & 8732 & $72 \cdot 26$ & $279 \cdot 0$ \\
Mean & $11 \cdot 3$ & 1203 & $4 \cdot 66$ & $73 \cdot 0$ \\
SD & $101 \cdot 5$ & 11300 & $85 \cdot 00$ & $390 \cdot 9$ \\
Maximum & $65 \cdot 3$ & 6900 & $64 \cdot 50$ & $174 \cdot 1$ \\
Minimum & 22 & 22 & 22 \\
No of subjects & 22 & 22 & \\
\hline
\end{tabular}

(preterm, full term) as a factor. Multiple regression analysis including a dummy independent variable based on type of birth was used to fit parallel regression lines to the data where appropriate. ${ }^{14}$ These techniques were applied using postconceptional age rather than time since birth as an independent variable. The resulting models can if necessary be used to predict the outcome of comparisons between preterm and full term infants of similar ages expressed as time since birth.

Standárd errors are denoted throughout by SE. Where error limits bound a mean point value, SE refers to the standard error of the mean. Where error limits about a regression line are given, SE refers to the standard error of the estimated mean.

\section{Results}

Figs 1, 2, and 3 show the individual term data for weight, crown-heel length, and bone mineral con-

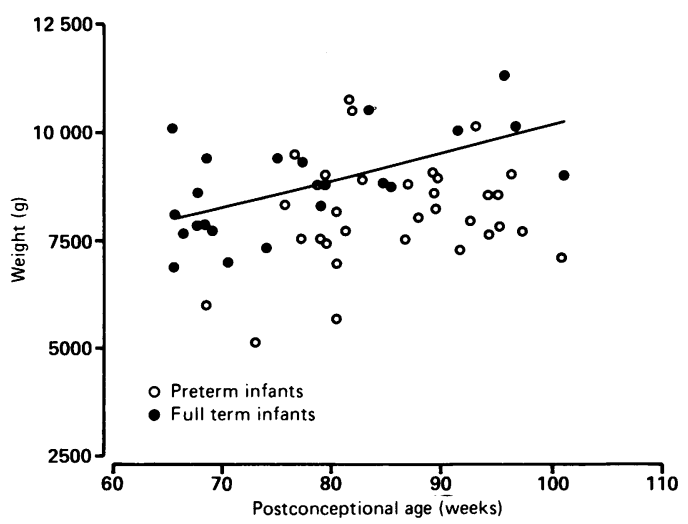

Fig 1 The association between body weight and postconceptional age in preterm and full term infants (endpoint data). The regression line shown fits the data on the full term infants.

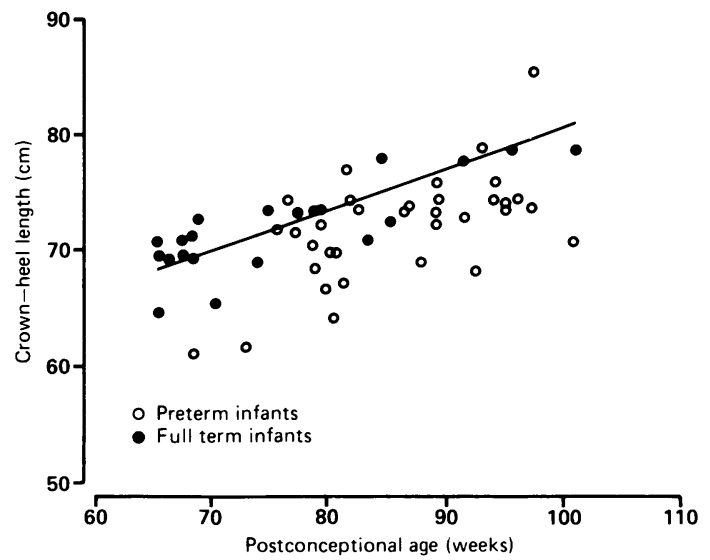

Fig 2 The association between crown-heel length and postconceptional age in preterm and full term infants (endpoint data). The regression line shown fits the data on the full term infants.

tent in relation to postconceptional age. Although in previous studies of younger infants it had been necessary to apply logarithmic transformations to all three measurements, 2815 there was no evidence in the current endpoint data that such a transformation was necessary at these higher postconceptional ages. Linear regression analysis was therefore applied to the raw data, starting with the observations on the full term infants. The equations, correlation coefficients, and associated significance levels of the resulting regression lines shown in figs 1 to 3 were: 


$$
\begin{array}{rlr}
\mathrm{W} 3 & =3873+62 \cdot 96 \cdot \mathrm{PA} 3 \mathrm{~g} & \mathrm{r}=0 \cdot 59, \mathrm{p}<0 \cdot 005 \\
\mathrm{CHL} 3=46 \cdot 00+0 \cdot 3402 \cdot \mathrm{PA3} \mathrm{cm} & \mathrm{r}=0 \cdot 83, \mathrm{p}<0 \cdot 001 \\
\text { BMC3 }=-16 \cdot 80+3 \cdot 832 \cdot \mathrm{PA} 3 \mathrm{mg} / \mathrm{cm} & \mathrm{r}=0 \cdot 60, \mathrm{p}<0 \cdot 005
\end{array}
$$

Preliminary inspection of the distributions of the observations on preterm infants relative to the regression lines shown in figs 1 and 2 indicated that weight and crown-heel length may be reduced in preterm infants relative to full term infants of comparable postconceptional age. In contrast, inspection of the results shown in fig 3 led us to conclude that there was no clear difference between values of bone mineral content in preterm and full term infants.

Regression analysis of the weight data for preterm infants shown in fig 1 resulted in a regression line having a slope not significantly different from the line illustrated. Analysis of variance and covariance showed type of birth (whether preterm or full term) to be a significant factor $(p<0.005)$ and multiple regression analysis was therefore performed using type of birth as a dummy variable. The two parallel lines which resulted are shown in the model illustrated in fig 4. The group centroid is indicated on each regression line; the ends of each line indicate the limits of the data. The common slope was $50 \cdot 2$ $\mathrm{g} /$ week (standard error of the slope, $\mathrm{SES}=16.4$ $\mathrm{g} /$ week), the lower of the two intercepts was $3851 \mathrm{~g}$ and the difference of the intercepts was $1008 \mathrm{~g}$ $(\mathrm{SE}=341 \mathrm{~g})$; the time separation of the two lines was therefore approximately 20 weeks. The multiple correlation coefficient was $0 \cdot 44$.

Similar analysis of the data for crown-heel length for preterm infants shown in fig 2 also resulted in a

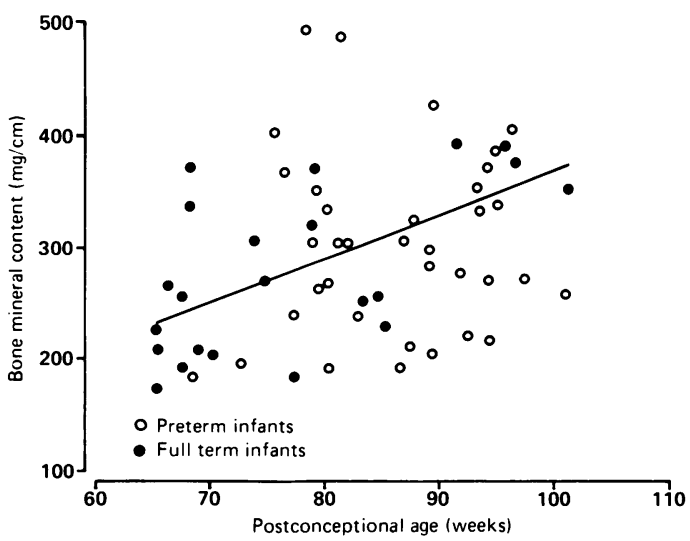

Fig 3 The association between bone mineral content of the mid-forearm and postconceptional age in preterm and full term infants (endpoint data). The regression line shown fits the data on the full term infants.

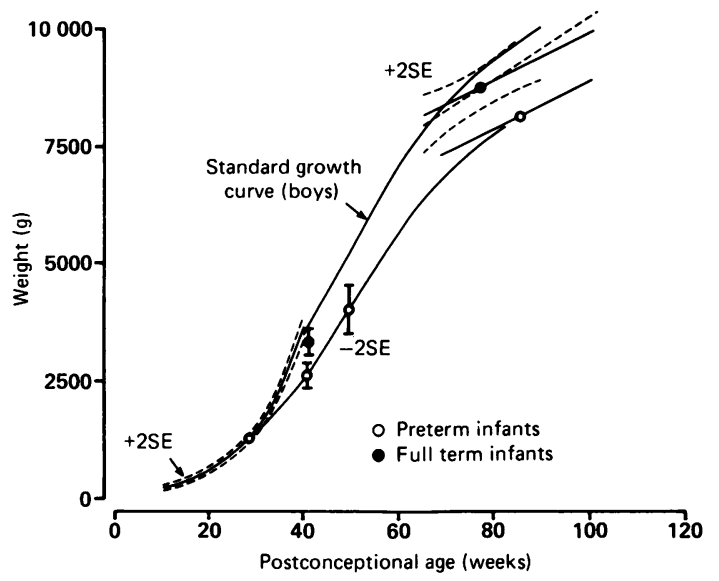

Fig 4 Model of changes in weight with increasing postconceptional age in preterm and full term infants. $S E$ denotes standard error of the mean for point values and standard error of the estimated mean for regression lines.

line with a slope not significantly different from the line illustrated, and analysis of variance and covariance again showed type of birth to be a significant factor $(p<0.001)$. The two parallel lines resulting from multiple regression analysis of the endpoint data are shown in the model illustrated in fig 5 . Their common slope was $0.313 \mathrm{~cm} /$ week (SES $=0.045$ $\mathrm{cm} /$ week), the lower intercept was $44.50 \mathrm{~cm}$ and the difference of the intercepts was $3.76 \mathrm{~cm}(\mathrm{SE}=0.935$ $\mathrm{cm})$; the time separation of the two lines was

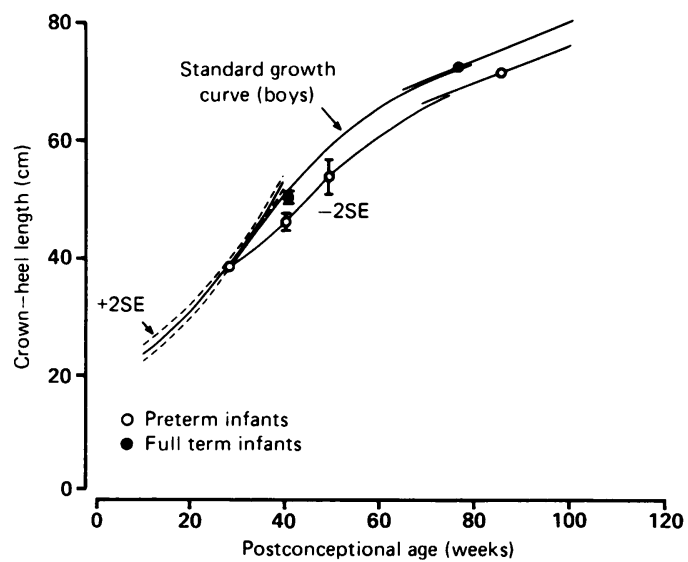

Fig 5 Model of changes in crown-heel length with increasing postconceptional age in preterm and full term infants. $S E$ denotes standard error of the mean for point values and standard error of the estimated mean for regression lines. 
approximately 12 weeks. The multiple correlation coefficient was 0.49 .

Analysis of variance and covariance did not show type of birth to be a significant factor in the 'term data' for bone mineral content (fig 3) and a single regression line was therefore fitted to the combined observations on preterm and full term infants. That common line is shown in the model illustrated in fig 6. Its slope was $2.43 \mathrm{mg} / \mathrm{cm} /$ week (SES $=0.96$ $\mathrm{mg} / \mathrm{cm} /$ week) and it passed through the value 286.8 $\mathrm{mg} / \mathrm{cm}$ at 80 weeks' postconceptional age $(\mathrm{r}=0.32$; $\mathrm{p}<0.02$ ). The error bars drawn in fig 6 about the common line indicate the 2SE limits of the estimated mean (that is, the ordinate of the regression line at any postconceptional age).

Figs 4, 5, and 6 contain exponential curves from 10 to 40 weeks of age based on our previously published data on growth in utero ${ }^{15}$; 2 SE limits of the estimated mean logarithmic values were computed at equally spaced intervals and antilogarithms taken to derive the error limits shown. In each figure the following are also included:

(1) A point on the in utero curve plotted at the mean gestational age of group $P$. This is the estimated mean value of the independent variable at birth for the preterm infants.

(2) The mean values with $2 \mathrm{SE}$ limits of the term data for groups $\mathrm{P}$ and $\mathrm{F}$ (from table 1). In the case of group $F$, infants with term data comprised only a small subset $(n=8)$ of those with endpoint data $(n=22)$.

(3) The mean value with $2 \mathrm{SE}$ limits of the

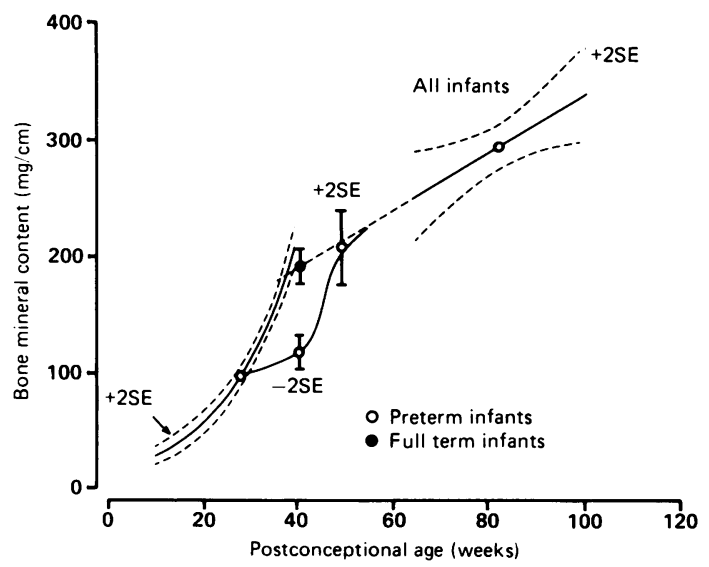

Fig 6 Model of changes in bone mineral content of the mid-forearm with increasing postconceptional age in preterm and full term infants. SE denotes standard error of the mean for point values and standard error of the estimated mean for regression lines. intermediate data for group P (from table 2); again infants with those data comprised only a small subset $(n=7$ or 8$)$ of those with endpoint data $(n=33$ or 36$)$.

(4) A smooth free hand curve joining the mean values described above for preterm infants with the regression line or lines representing the endpoint data for preterm infants.

For weight and crown-heel length, standard curves are available which describe the expected mean values from age 28 weeks onwards ${ }^{11}$; the standard weight curve for full term boys is shown in fig 4 . The same figure also contains the regression line with its 2SE limits for the endpoint data on the full term group (dotted). In fig 5 the standard crownheel length curve for boys is shown from 28 weeks.

Thus figs 4,5 , and 6 summarise how the mean values of weight, crown-heel length, and bone mineral content probably changed as postconceptional age increased in these groups of preterm and full term infants. In general terms, those figures should not be taken to describe the paths likely to be followed by any individual. For example, the paths followed by the individuals in the current study might have contained small plateau regions, not apparent in this set of data, that would only have been shown by frequently repeated sequential measurements throughout the whole age span.

Within the limitations of the available data, however, fig 4 clearly shows the sigmoidal shape of the growth curve for weight in both groups. Our in utero curve and the standard curve match up at $\mathbf{4 0}$ weeks; for the full term infants, the mean weight near to the time of birth, 3344 (284) g (2SE limits; $95 \%$ confidence interval is a factor of 1.18 greater), was consistent with the standard mean value of $3650 \mathrm{~g}$ approximately. The endpoint data on the full term infants were also consistent with the standard data for boys, the error limits of the regression line for full term infants (dotted) encompassing the standard curve. At all postconceptional ages group $P$ had a lower mean weight than group $F$. For both the term data and intermediate data on group $P$, the mean value of weight was significantly lower than the standard value $(p<0.001)$, and the two parallel lines representing the endpoint data had significantly different intercepts $(p<0.005)$ as indicated above. The absolute mean weight difference between the groups increased with time, from about $700 \mathrm{~g}$ at 40 weeks to about $1100 \mathrm{~g}$ at 80 weeks. Relative to mean values in full term infants, these differences amounted to deficits of $21 \%$ and $13 \%$. Viewing the two curves in fig 4 in a different way, the time lag between the two groups increased as postconceptional age increased: at about 40 weeks the preterm infants lagged behind the full term infants by about 


\section{Horsman, Ryan, Congdon, Truscott, and Simpson}

five weeks; around 80 weeks' postconception the preterm infants were about 20 weeks behind.

Fig 5 similarly shows the sigmoidal shape of the growth curve for crown-heel length in both groups. Our previously published regression equation describing length increase in utero systematically overestimated crown-heel length in the postconceptional age range 30 to 40 weeks; the standard curve in fig 5 lies below the exponential approximation to the in utero data. (The systematic error is evidence that the exponential approximation was invalid at the upper extreme of the age range examined.) With regard to the full term infants, the term data for crown-heel length (mean $50.38(0.94) \mathrm{cm} ; 2 \mathrm{SE}$ limits) tended to be low but were reasonably consistent with the standard value $(51.5 \mathrm{~cm}$ approximately). At higher postconceptional ages, the standard curve approached almost tangentially the upper of the two parallel regression lines describing the endpoint data. At all postconceptional ages, group $P$ had lower mean values of crown-heel length than group F. For both the term data and intermediate data on group $P$, mean crown-heel length was significantly lower than the standard value $(\mathrm{p}<0.001$ and 0.02 respectively), and the two parallel lines representing the endpoint data had significantly different intercepts $(p<0 \cdot 001)$ as mentioned above. The absolute difference between the groups in mean crown-heel length remained essentially constant from 40 weeks onwards at about $5 \mathrm{~cm}$. Relative to values in full term infants, this amounted to a length deficit of about $10 \%$ at 40 weeks and $7 \%$ at 80 weeks. Again the time lag between the two groups increased as postconceptional age increased; at about 40 weeks the preterm infants lagged behind the full term infants by about five weeks; around 80 weeks' postconception the preterm infants were more than 10 weeks behind.

Fig 6 illustrates the divergence and reconvergence of the mean bone mineral content values in the preterm and full term groups. For group $F$, the mean value of the term data lay very close to the line produced by backward extrapolation of the regression line through the endpoint data, that is, it appears from these results that the rate of increase of bone mineral content in the full term infants was constant from birth onwards. The postnatal rate of mineral accretion was less than the rate appertaining in utero, even at the very lowest gestational ages investigated in previous studies. The mean value of bone mineral content for the term data (group F) was somewhat lower than the mean value predicted by the exponential in utero curve; this finding was anticipated on the basis of the rather low mean value of crown-heel length observed in this subset of the full term infants (fig 5). The mean value of the intermediate data for bone mineral content on the preterm infants lay close to the line joining the data on full term infants, implying that the deficit evident in the preterm infants at 40 weeks had been largely made up at 50 weeks' postconception. The mean values of the term data were significantly different between the two groups $(\mathrm{p}<0.001)$, as expected from previous studies ${ }^{12}$; near 40 weeks the mean value for group $\mathrm{P}$ was about $60 \%$ of the mean value for group $F$.

\section{Discussion}

Our weight and crown-heel length measurements are consistent with the common clinical observation that in the postconceptional age range 65 to 100 weeks, preterm infants are lighter and shorter than their full term peers. ${ }^{9}$ In the groups we studied the weight deficit was about $1000 \mathrm{~g}$ and the crown-heel length deficit was about $4 \mathrm{~cm}$.

Those results, coupled with previous observations in preterm infants of substantial deficits in bone mineralisation at about 40 weeks' postconception, ${ }^{12}$ led us to expect that there might be a systematic, longer term mineralisation deficit in such cases. The null hypothesis tested in the analysis presented above was that no mineralisation deficit existed after 65 weeks' postconception, and contrary to expecta tions that hypothesis could not be rejected on the basis of the observations. Our present conclusion is therefore that we have no evidence of a longer term mineralisation deficit in preterm infants, despite their reduced body size, where mineralisation deficit here refers specifically to the mineral content of a $1.0 \mathrm{~cm}$ length of the mid-forearm, summated over the two bones. ${ }^{3}$

Although we and others have used that measurement to quantify osteopenia of prematurity in the neonate, ${ }^{1247}$ it would not be valid to conclude from the results of this study that osteopenia of prematurity has been shown to be a self remitting condition with no long term consequences for skeletal status in the broadest sense. Mineralisation of the forearm bones at their metaphyses, which were not monitored in our study, might be affected by prematurity; there may also be persistent effects of prematurity on mineral accretion at other skeletal sites that are not mirrored in changes at the mid-forearm site. ${ }^{16}$

Furthermore, as prematurity is clearly associated with changed bone morphology (that is, reduced length of the long bones), the rate of matrix synthesis must itself be reduced, perhaps with secondary effects on mineralisation. For example, the lack of a mineralisation deficit in the midforearm may be partly a consequence of the fact that 
linear growth is retarded in preterm infants, the available mineral supply being deposited in the diaphysis rather than in the metaphyses, because the latter grow less rapidly than they should in those cases. The bones of preterm infants are not only shorter; the distribution of mineral within the forearm bones appears to differ from that in full term infants. In such a situation, the limits of our present methodological approach have been reached, and future studies may need to include, for example, measurements of the length of the mineralised region in the radial diaphysis.

There are currently few published results with which our endpoint data can be compared. Although several groups have used peripheral absorptiometry to examine bone mineralisation in the first year of life, ${ }^{9}{ }^{16-24}$ currently no other published study has involved both preterm and full term infants in the postconceptional age range 65 to 100 weeks. Previously published data from Chan and coworkers on somewhat younger full term infants ${ }^{23}$. and preterm infants, ${ }^{17}$ who were rather heavier than our cases, however, are consistent with our findings. Comparison of their data from the two studies shows that by the postconceptional age of 56 weeks the mean value of bone mineral content observed in their preterm group $(103 \mathrm{mg} / \mathrm{cm})$ was similar to the mean value observed in their full term group $(110 \mathrm{mg} / \mathrm{cm})$.

If preterm and full term infants do in fact have very closely similar mean values of bone mineral content by about 60 weeks' postconception, yet differ substantially at $\mathbf{4 0}$ weeks, it is an obvious deduction that, in the interval 40 to 60 weeks, preterm infants must have a higher rate of mineral accretion than full term infants. Published data from several sources strengthen this conclusion and also highlight the large interindividual variability in the rate of mineral accretion. Between 40 and 56 weeks' postconception, preterm infants have been shown to increase their bone mineral content value by between $30 \%$ and $60 \%$ of the mean value observed in full term infants close to the time of birth. ${ }^{917} 18$ Over the same period term infants have been shown to increase their bone mineral content values by smaller amounts, in the range 11 to $45 \% .{ }^{20} 23$

Our observation of accelerated mineral accretion in the forearms of preterm infants between 40 and 60 weeks' postconception is therefore consistent with the findings of other workers. The acceleration appears to be of sufficient magnitude to reduce substantially the large mineral deficit which develops in preterm infants in the immediately postnatal period and which might otherwise persist into childhood. Detection of residual effects too small to be revealed by the current study would require a different experimental approach, perhaps involving radiography and frequent sequential observations of individuals throughout the whole span of postconceptional age under investigation.

While this work was being carried out SW Ryan was supported by a grant from the Special Trustees of The General Infirmary at Leeds while A Horsman, M Simpson, and JG Truscott were supported by the Medical Research Council. The authors are grateful to $\mathrm{Dr} L$ Burkinshaw for his advice and guidance in the statistical analysis of the data.

\section{References}

1 James JR, Congdon PJ, Truscott J, Horsman A, Arthur R. Osteopenia of prematurity. Arch Dis Child 1986;61:871-6.

${ }^{2}$ Horsman A, Ryan SW, Congdon PJ, Truscott JG, James JR. Osteopenia in extremely low birthweight infants. Arch Dis Child 1989;64:485-8.

3 James JR, Truscott J, Congdon PJ, Horsman A. Measurement of bone mineral content in the human fetus by photon absorptiometry. Early Hum Dev 1986;13:169-81.

${ }^{4}$ Steichen JJ, Gratton TL, Tsang RC. Osteopenia of prematurity; the cause and possible treatment. J Pediatr 1980;96:528-33.

5 Gross SJ. Bone mineralization in preterm infants fed human milk with and without mineral supplementation. $J$ Pediatr 1987;111:450-8.

${ }^{6}$ Seino Y, Ishii T, Shimotsuji T, Ishida M, Yabuuchi H. Plasma active vitamin $\mathrm{D}$ concentration in low birth weight infants with rickets and its response to vitamin D treatment. Arch Dis Child $1981 ; 56: 628-32$.

7 Greer FR, McCormick A. Improved bone mineralization and growth in premature infants fed fortified own mother's milk. J Pediatr 1988;112:961-9.

${ }^{8}$ Horsman A, Ryan SW, Congdon PJ, Truscott JG, Simpson M. Bone mineral accretion rate and calcium intake in preterm infants. Arch Dis Child 1989;64:910-8.

9 Greer FR, McCormick A. Bone mineral content and growth in very-low-birth-weight premature infants. Am J Dis Child 1987; 14:179-83.

${ }^{10}$ Karniski W, Blair C, Vitucci JS. The illusion of catch-up growth in premature infants. Am J Dis Child 1987;141:520-6.

1 Gairdner D, Pearson J. A growth chart for premature and other infants. Arch Dis Child 1971;46:783-7. (Revised, Ware: Castlemead Publications, 1985.)

12 Parkin JM, Hey EN, Clowes JS. Rapid assessment of gestational age at birth. Arch Dis Child 1976;51:259-63.

${ }^{13}$ Hittner HM, Hirsch NJ, Rudolph AJ. Assessment of gestational age by examination of the anterior vascular capsule of the lens. J Pediatr 1977;91:455-8.

14 Armitage P. Statistical methods in medical research. Oxford: Blackwell Scientific Publications, 1971.

15 Ryan S, Congdon PJ, James J, Truscott J, Horsman A. Mineral accretion in the human fetus. Arch Dis Child 1988;63:799-808.

${ }^{16}$ Hillman LS. Bone mineral content in term infants fed human milk, cow milk-based formula, or soy-based formula. J Pediatr 1988:113:208-12.

17 Chan GM, Mileur LJ. Posthospitalisation growth and bone mineral status of normal preterm infants. Am J Dis Child 1985;139:896-8.

is Abrams SA, Schanler RJ, Garza C. Bone mincralisation in former very low birth weight infants fed human milk or commercial formula. J Pediatr 1988;112:956-60.

19 Greer FR, Searcy JE, Levin RS, Steichen JJ, Asch PS, Tsang RC. Bone mineral content and serum 25-hydroxyvitamin D concentration in breast-fed infants with and without supplemental vitamin D. J Pediatr 1981:98:696-701. 
${ }^{20}$ Roberts CC, Chan GM, Folland D, Rayburn C, Jackson R. Adequate bone mineralisation in breast-fed infants. $J$ Pediatr 1981;99:192-6.

${ }^{21}$ Greer FR, Searcy JE, Levin RS, Steichen JJ, Steichen-Asche PS, Tsang RC. Bone mineral content and serum 25-hydroxyvitamin D concentrations in breast-fed infants with and without supplemental vitamin D: one year follow-up. J Pediatr 1982;100: 919-22.

22 Chan GM, Leeper L, Book LS. Effect of soy formulas on mineral metabolism in term infants. Am J Dis Child 1987;141: 527-30.

${ }^{23}$ Chan GM, Roberts CC, Folland D, Jackson R. Growth and bone mineralisation of normal breast-feeding infants and the effects of lactation on maternal bone mineral status. Am J Clin Nutr 1982;36:438-43.

${ }^{24}$ Steichen JJ, Tsang RC. Bone mineralisation and growth in term infants fed soy-based or cow milk-based formula. J Pediatr 1987;110:687-92.

Correspondence to Dr A Horsman, MRC Bone Mineralisation Group, Department of Medical Physics, The General Infirmary, Great George Street, Leeds LS1 3EX.

Accepted 15 May 1989 